\title{
Kronik Hastalık Yönetimi İçin Bir Rehber: Kronik Bakım Modeli*
}

\author{
A Guide for Chronic Disease Management: The Chronic Care Model
}

\author{
Kübra İNCİRKUŞ ${ }^{* *}$, Nursen Ö. NAHCIVAN ${ }^{* * *}$
}

İletişim: Kübra İNCİRKUŞ Adres/Address: İstanbul Üniversitesi Florence Nightingale Hemşirelik Fakültesi, Halk Sağlığı Hemşireliği Anabilim Dalı, Abide-i Hürriyet Caddesi, Şişli/İstanbul Tel: 021244000 00/27134 E-mail: kincirkus@istanbul.edu.tr

\section{$\ddot{O} Z$}

Günümüzde kronik hastalıkların giderek yaygınlaşması, kronik hastalık kontrolü ve toplum temelli hastalı yönetimi programlarının önemini ortaya koymaktadır. Kronik hastalı yönetimi, özellikle bakımın koordinasyonu ve sürekliliğini sağlamada, ekip çalışmasının desteklenmesinde, kronik hastalık bakımının kalitesinin geliştirilmesinde, beklenen hasta sonuçlarını iyileştirmede ve bakımın maliyetlerini azaltmada önemli ve pratik bir yöntemdir. Kronik hastalı yönetimi için çeşitli modeller ileri sürülmesine rağmen en çok kullanılan ve en etkili kabul edileni Kronik Bakım Modelidir. Wagner ve arkadaşları tarafindan tanımlanan model, genel olarak altı temel bileşeni tanımlamaktadır. Bunlar; (1) Toplum kaynakları ve politikalar, (2) Karar verme desteği, (3) Sağllk bakım organizasyonu, (4) Öz-yönetim desteği, (5) Să̆llk hizmetleri sunum planı ve (6) Klinik bilgi sistemleridir. Model; birbiriyle bağlantılı olan bu altı bileşen doğrultusunda hastaların sağglk/bakım sonuçlarını geliştirmek için tasarlanmıştır. Başarılı bir kronik hastalık yönetimi için sağlık profesyonellerinin geleneksel tedavi ve bakım anlaylşı yerine hasta merkezli, multi-disipliner ve kanıt temelli yaklaşımlar hakkında bilgi ve farkındalıklarının artması önemlidir. Bu derleme makalede, genelde kronik hastalı̆̆ olan bireylerle çalışan sağllk profesyonellerine özelde hemşirelere kronik hastalık yönetiminde bir rehber olarak Kronik Bakım Modeli'ni tanitmak; modelin kronik hastalıkların yönetiminde kullanılmasinda yol göstermek amaçlanmıştır.

Anahtar Kelimeler: Kronik hastalık, kronik hastalık yönetimi, hemşirelik, Kronik Bakım Modeli.

\section{ABSTRACT}

Currently the increasing prevalence of chronic diseases reveals the importance of chronic disease control and communitybased disease management programs. Chronic disease management; is an important and practical method especially in providing the coordination and continuity of care, promoting teamwork, improving the quality of chronic disease care and patient outcomes, reducing the costs of care. Despite the various models for chronic disease management been offered, the most widely used and most effective acceptable is the Chronic Care Model. The model developed by Wagner et al, generally defines six major components. These are: (1) Community resources and policies, (2) Decision support, (3) Organization of health care, (4) Self-management support, (5) Delivery system design and (6) Clinical information systems. Model, accordance with the six components which are connected with each other, is designed to improve patients results of health/care. Instead of traditional treatment and care approach, increasing knowledge and awareness about patient-centered, multi-disciplinary and evidence-based approaches is important for the successful chronic disease management. In this review article, aimed to present the Chronic Care Model as a guide in chronic disease management and advise for using of the model in chronic disease management for the health professionals (especially for nurses) working with patient which have chronic diseases.

Key Words: Chronic disease, chronic disease management, nursing, The Chronic Care Model

*14.Ulusal Halk Sağllğı Kongresi’nde poster bildiri olarak sunulmuştur (4-7 Ekim 2011, Trabzon), **Arş. Gör. İstanbul Üniversitesi Florence Nightingale Hemşirelik Fakültesi, ***Prof. Dr. İstanbul Üniversitesi Florence Nightingale Hemşirelik Fakültesi

Yazının gönderilme tarihi: 15.11.2013

Yazının basım için kabul tarihi: 05.11.2014 


\section{GíRiş}

Tüm dünyada beklenen yaşam süresinin uzamasıyla birlikte, kronik hastalıkların görülme sıklığı giderek artmaktadır. Dünya Sağlık Örgütü’nün raporuna göre; 2008 yılında meydana gelen ölümlerin \%63'ü kronik hastalıklar (kalp-damar hastalıkları, kanserler, diyabet ve kronik solunum yolu hastal1kları) nedeniyle olmuştur. Bu oranın 2010-2020 y1lları arasında \%15 artacağı; bu artışın özellikle düşük ve orta gelirli ülkelerde en fazla olacağı tahmin edilmektedir (WHO 2011). Ülkemizde de nüfusun yaşlanmasına paralel olarak, hastalık yükü giderek artmakta ve bu hastalıkların büyük bir bölümünü kronik hastalıklar oluşturmaktadır (Mollahaliloğlu ve ark. 2007). Ulusal raporlarda, ülkemizde toplam ölümlerin \%71'inin kronik hastalıklar nedeniyle olduğu (Erkoç ve Yardım 2011) ve ölüme neden olan ilk on hastalıktan yedisinin kronik hastalıklar olduğu belirtilmektedir (Bora-Başara, Dirimeşe, Özkan ve Varol 2006). Günümüzde kronik hastalıkların giderek yaygınlaşması, kronik hastalık kontrolü ve toplum temelli hastalık yönetimi programlar1nın önemini ortaya koymaktadır (Cranston 2006; Davis, Wagner ve Groves 1999).

Kronik hastalıkların yönetimi, hastanın öz-yönetim becerisi kazanması için çeşitli eğitim öğretim yöntemleriyle güçlendirilmesi gibi hastalığın tedavisinden daha fazlasını kapsar (Beaglehole ve ark. 2008; Haskett 2006). Etkili bir hastalık yönetimiyle hastalık belirtilerinin, acil birimlere başvuruların ve hastaneye yatışların azaltılması, hastalığın fizyolojik ve psikolojik etkilerinin sınırlandırılması, bağımlılığın önlenmesi ve yaşam kalitesinin artırılması sağlanabilmektedir (Demirağ 2009; Haskett 2006). Kronik hastalık yönetimi, özellikle bakımın koordinasyonu ve sürekliliğini sağlamada, ekip çalışmasının desteklenmesinde, kronik hastalık bakımının kalitesinin geliştirilmesinde, beklenen hasta sonuçlarını iyileştirmede ve bakımın maliyetlerini azaltmada önemli ve pratik bir yöntemdir (Clark ve Gong 2000; Geyman 2007; Rothman ve Wagner 2003). Başarılı kronik hastalık bakım uygulamaları genellikle çok disiplinli ve koordine bir bakım ekibini kapsamaktadır. Uygun eğitim ve ekip çalışma- s1 ile desteklenen birinci basamak sağlık bakım profesyonelleri, bütüncül ve kesintisiz kronik hastalık yönetimini sağlayacaklardır (Wagner 2000).

Sağlık profesyonelleri içinde hemşireler, ekibin önemli bir üyesidir ve kronik hastalıkların yönetiminde giderek daha fazla lider roldedirler (ICN 2010). Literatürde en başarılı kronik hastalık yönetimi uygulamalarında mutlaka hemşirelerin yer aldığı belirtilmektedir (Wagner 2000). Hemşireler yaptıkları uygulamaların doğası gereği hastalarla daha fazla zaman geçirme ve iletişim kurma firsatına sahiptirler (Haskett 2006; ICN 2010). Dolayısı ile bakım uygulamalarında ön s1ralarda yer alan hemşireler hasta eğitimini, bakımda sürekliliği ve işbirliğini sağlar; hastalar, bakım vericiler ve toplumla iletişim kurar; bakım kalitesinin artırılması için teknolojiyi kullanır ve uzun süreli tedavilerde hastanın tedaviye uyumunu destekler (ICN 2010). Nitekim çeşitli araştırma raporlarında kronik hastalı$\breve{g} 1$ olan bireylere uygulanan planlı hemşire ziyaretlerinin; diyabetik hastaların hemoglobin A1c düzeylerinde ve hastaneye yatışlarda belirgin bir azalma sağladığı (Sadur ve ark. 1999), diyabetik hastaların sağlık davranışlarını ve bakım sonuçlarını olumlu yönde geliştirdiği (Renders ve ark. 2001), koroner kalp hastalığı riski olan grupların hedeflenen kolesterol konsantrasyonlarına ulaşmasında birinci basamakta uygulanan rutin tedaviden 2,5 kat daha etkili olduğu (Becker ve ark. 1998), kronik obstrüktif akciğer hastalığ (KOAH) olan hastaların öz-bakım davranışlarını geliştirdiği, solunum fonksiyon test sonuçlarında anlam11 iyileşme sağladığı, hastaneye yatış oranlarında ve bakım hizmetlerinde maliyeti azalttığı gösterilmiştir (Duangbubha ve ark. 2013).

Kronik hastalık yönetimini konu alan çeşitli yayınlarda, tedaviye karar verilirken hastaların \%91'inin katılımının olmadığı (Braddock, Edwards, Hasenberg, Laidley ve Levinson 1999), hekimlerin iş yükü nedeniyle hastalara yeterince zaman ayıramadıkları (TTB 2011a) bildirilmektedir. Yeterince bilgilendirilmeyen ve katılımı sağlanamayan pasif hastaların davranış değiştirmede daha yetersiz uyum ve daha olumsuz sağlık bakım sonuçları gösterdikleri belirtilmektedir (He- 
isler, Bouknight, Hayward, Smith ve Kerr 2002). Ayrıca kronik hastalık yönetiminin başarısını etkileyen nedenler arasında, kronik hastalık yönetiminde görev alacak sağlık profesyonellerinin sayılarının azlığı, bakım koordinasyonundaki yetersizlikler, klinik karar destek ve bilgi sistemlerinin eksikliği ve mevcut sisteme entegre edilmemesinin yanı sıra, sağlik profesyonellerinin eğitiminde kronik hastalıkların öz-yönetimi yerine geleneksel tedavi ve bakım anlayışının yer alması gösterilmektedir (Akalın, Durusu-Tanrıöver ve Sayran 2012; Bodenheimer, MacGregor ve Stothart 2005; TTB 2011a).

Kronik hastalık yönetiminin başarısında önemli bir sacayağını oluşturan sağlık profesyonellerinin geleneksel tedavi ve bakım anlayışı yerine hastayı merkeze alan, multidisipliner ve kanıt temelli yaklaşımlar hakkında bilgi ve farkındalıklarının artması önemlidir. $\mathrm{Bu}$ bağlamda bu derleme makalede, genelde kronik hastalığ 1 olan bireylerle çalışan sağlık profesyonellerine özelde hemşirelere kronik hastalık yönetiminde bir rehber olarak Kronik Bakım Modeli'ni tanıtmak; modelin kronik hastalıkların yönetiminde kullanılmasında yol göstermek amaçlanmıştır.

\section{KRONIKK BAKIM MODELI}

Kronik hastalık yönetimi için çeşitli modeller ileri sürülmesine rağmen en iyi bilinen, en çok kullanılan ve en etkili kabul edileni "Kronik Bakım Modelidir" (Beaglehole ve ark. 2008; Piatt ve Zgibor 2007). Kisa süreli akut yaklaşımlarla kıyaslandığında uzun süreli kronik bakım yönetimi uygulamalarının öneminin anlaşıldığı günümüzde; Kronik Bakım Modeli kronik hastalık yönetiminde toplumsal ve ekonomik yükün giderek artması sonucunda bakımın kalitesini artırmak ve bakımın maliyetini azaltmak amaciyla bir rehberlyol haritası olarak ortaya konmuştur (Bodenheimer, Wagner ve Grumbach 2002a; Geyman 2007; Hennesey, Suter ve Harrison 2010; Moroz 2007; Wagner 2002).

Wagner ve arkadaşları tarafından tanımlanan modelin anahtar noktası, sağlık bakım ekibi ile hasta ara- sında verimli bir etkileşimin olmasıdır (Bodenheimer ve ark. 2002a; Rothman ve Wagner 2003; Solberg, Trangle ve Wineman 2005). Modele göre, bilgi, beceri ve güven ilişkisi ile motive edilmiş "hasta" ile hastalık konusunda gerekli olan uzmanlık, deneyim, bilgi ve kaynaklara sahip "sağlık bakım ekibi” birlikte var olan kaynakları kullanarak yüksek kalitede bakım için etkili kararlar verebilecek ve kronik hastalık bakımını etkin şekilde yönetebilecektir (ICN 2010; Wagner ve ark. 2001). Kronik Bakım Modeli, primer sağlık hizmetleri ile sağlığın korunmasına ve geliştirilmesine yönelik hizmetleri ön plana çıkarmaktadır. Modelin amac1; kronik hastalığı olan bireylerin günlük bakımını akut ve tedavi edici bakımdan koruyucu, planlanmış ve toplum temelli bakıma dönüştürmektir. Model doğrultusunda yapılandırılan kronik hastalık yönetimi ile hastalar rutin olarak tanılanır, aktif katılımları ve ayrıntılı olarak bilgilendirilmeleri sağlanır, öz-yönetim için desteklenir. Bu doğrultuda en uygun tedavi ve izlem planlanarak bakım sonuçlarında ve kalitesinde iyileşme; sonuçta da hasta memnuniyeti beklenir (Bodenheimer ve ark. 2002a; Coleman, Austin, Brach ve Wagner 2009; Hennesey ve ark. 2010; Rothman ve Wagner 2003). Başka bir ifadeyle Kronik Bakım Modeli, hızlı bir çözüm veya sihirli bir değnek değil; karmaşık problemlerin çok boyutlu çözümüdür (Wagner 2002).

Kronik Bakım Modeli'nin kullanıldığı alanlar oldukça kapsamlıdır. Model sigara kullanımı, sağlıks1z beslenme, fiziksel hareketsizlik gibi önemli sağlık risk davranışlarını önleme ve kronik hastalıklardan korunmada kullanılmış ve olumlu sonuçlar elde edilmiştir (Glasgow ve ark. 2001; Hung ve ark. 2007). Ayrıca kronik hastalıklarla beraber görülen depresyonun yönetiminde (Mcevoy ve Barnes 2007), KOAH'lı bireylerde hastalık yönetiminin sağlanmasında (Adams ve ark. 2007; Duangbubha ve ark. 2013) ve bu hastalara sunulan evde bakım hizmetlerinin kalitesinin artırılmasında (Suter, Hennessey, Florez ve Suter 2011), sigara kullanımının tanılanması ve davranış değişiminin sağlanmasında (Carlini, Schauer, Zbikowski ve Thompson 2010), artrit- 
li hastaların bakımının planlanmasında (Rosemann, Laux, Szecsenyi ve Grol 2008) kullanılmıştır. Modelin astım, diyabet, hipertansiyon, kalp hastalıkları, artrit ve konjestif kalp yetmezliği gibi hastalıklarda uygulanması sonucunda, maliyet-etkin olduğu, acile/hastaneye gereksiz yatışları azalttı̆̆ı, yaşam kalitesini ve hasta memnuniyetini olumlu yönde etkilediği bulunmuştur (Bodenheimer, Wagner ve Grumbach 2002b; Geyman 2007; Rothman ve Wagner 2003; Wagner 2004). Model, birçok ülkenin sağlık sisteminde başarı ile kullanılmaktadır (Smidth, Christensen, Olesen ve Vedsted 2013).

Model genel olarak altı temel bileşeni tanımlamaktadır (Şekil 1). Bunlar; (1) Toplum kaynakları ve politikalar, (2) Karar verme desteği, (3) Sağlik bakım organizasyonu, (4) Öz-yönetim desteği, (5) Sağlık hizmetleri sunum planı ve (6) Klinik bilgi sistemleridir (Beaglehole ve ark. 2008; Solberg ve ark. 2005).

\section{KRONIKK BAKIM MODELI'NİN BİLEŞENLERİ}

Modelin birbiri ile sıkı ilişkiler içinde olan altı bileşeni aşağıda tanımlanmaktadır:

\section{Toplum Kaynaklart ve Politikalar (Community Re-} sources and Policies): Toplum kaynakları ile sağlı bakım sistemleri arasındaki işbirliğini ifade eder (Bonomi, Wagner, Glasgow ve VonKorff 2002). Toplumda hastaların gereksinimlerine yönelik oluşturulmuş çok çeşitli toplum kaynaklarının (akran destek grupları, eğitim programları, egzersiz programları, medya gibi) harekete geçirilmesini; hastaların hastalıkları ile baş etmelerini kolaylaştırmak için hastane veya evde bakım kurumları ile bağlantı kurulmasını içerir (Wagner 2000; Zwar ve ark. 2006). Kronik hastalık yönetiminin desteklenmesinde toplum kaynakları ve politikaların kullanılmasına çok çeşitli örnekler verilebilir. Sağlıklı beslenme ve egzersiz, kilo kontrolü, siga-

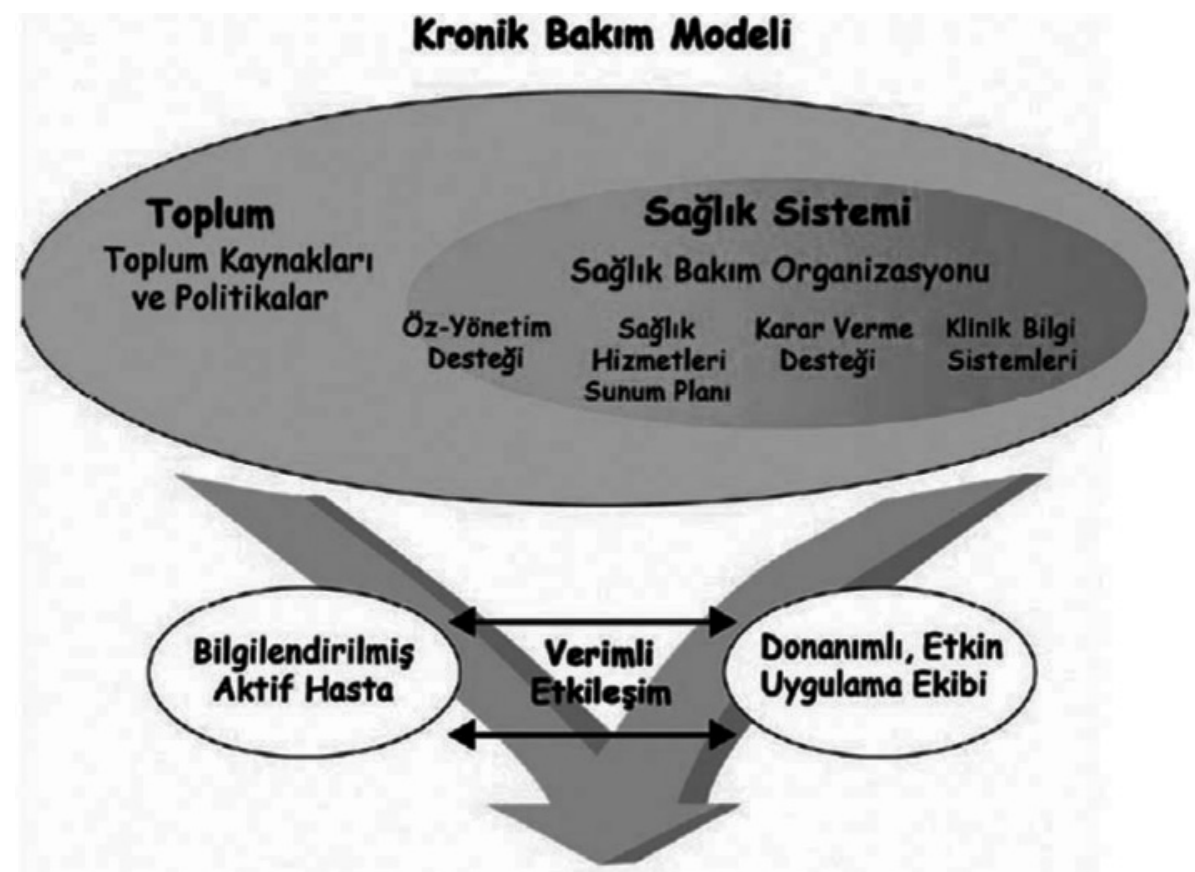

Geliştirilmiş Sonuçlar

Şekil 1: Kronik Bakım Modeli

(Kaynak: Wagner, E. H. (1998). Chronic disease management: What will it take to improve care for chronic illness? Effective Clinical Practice, 1: 2-4). 
rayı bırakma vb. konularda sağlığı koruyan ve geliştiren programların planlanması ve toplum katılımının sağlanması, toplum temelli uygulamaların etkili kullanımı ve desteklenmesi, uygun yürüme alanlarının sağlanması, sağlıklı gıda ürünlerinin fiyatlarının azaltılması gibi konularda politikaların oluşturulması, sağlık bakım ekibi ile toplum liderleri ve ilaç şirketleri arasında işbirliğinin sağlanması, bilgi sistemlerinin sağlanması bu örnekler arasında yer almaktadır (Barr ve ark. 2003; Stellefson, Dipnarine ve Stopka 2013).

\section{Sağlık Bakım Organizasyonu (Organization of}

Health Care): Kronik hastalık yönetiminde, değerlendirilebilir ve ölçülebilir amaç ve hedefleri içeren programların planlanması önemli bir bileşendir (Barr ve ark. 2003). Kronik Bakım Modelinin bu bileşeni, bakım için gerekli olan altyapının oluşturulmasını, iyi planlamayı, kaynakların maliyet-etkin kullanılmasını ve yönetilmesini, kalite geliştirme çalışmalarını, kurumlar arasında koordinasyonun sağlanmasını, hizmete uygun politika oluşturma ve hizmetleri planlamayı, öz-yönetim programlarının yaygınlaştırılmasını sağlayan kurumların desteklenmesini, etkili yeni stratejilerin ve bu stratejileri yönetecek liderlerin belirlenmesini içermektedir (ICN 2010; Stellefson ve ark. 2013). Kronik hastalık bakımının güçlü liderler tarafından desteklenmesi; motivasyonun sağlanması, kaynakların korunması ve karşılaşılacak güçlüklerin azaltılmasinda etkili bir rol oynayacaktır (Bonomi ve ark. 2002; Wagner 2002).

Türkiye'de Sağlıkta Dönüşüm Programı kapsamında aile hekimliği uygulamaları 2005 yılında başlamış olup 2010 yılının sonunda tüm Türkiye'de uygulamaya geçilmiştir (Erkoç ve Yardım 2011). Sağlıkta Dönüşüm sonrasında kronik hastalıkların önlenmesi ve kontrolü ile ilgili; Türkiye Kalp ve Damar Hastalıkları Önleme ve Kontrol Programı, Solunum Yolu Hastalıklarına Karşı Küresel İttifak (GARD), Türkiye Obezite Eylem Programı, Tütün Kontrolü Çerçeve Sözleşmesi gibi çeşitli çalışma ve projeler uygulamaya konmuştur (Akdağ 2008; Erkoç ve Yardım 2011). Sağlık Bakanlığı’nın “Türkiye Kardiyovasküler Hastalıklar- dan Korunma ve Kontrol Programı" adlı raporunda (2008); kronik hastalıkların önlenmesi ve kontrolünde yeni bir yaklaşıma ihtiyaç duyulduğu belirtilmektedir. Ülkemizde kronik hastalıkların etkisi altında olan nüfusun büyük oranda toplumda yaşadığı düşünülürse birinci basamakta ve evde bakım hizmetlerinde kronik hastalık yönetiminin önemi tartışmasız bir gerçektir. Her türlü önlemlere rağmen gelişen kronik hastalıkların etkin tedavisi ve bakımı için Kronik Bakım Modeline dayalı kronik hastalık yönetiminin yapılandırılması önerilen çabalar arasındadır.

\section{Sağlık Hizmetleri Sunum Planı (Delivery System}

Design): Sağlık bakım ekibinin rollerinin açık ve net olarak tanımlanmasını içerir (Barr ve ark. 2003). Kronik hastalık bakım uygulamalarında planlanmış hastalık yönetiminden akut bakıma kadar her uygulamada sağlık bakım ekibinin rolleri, sorumluluklar1 ve işgücü açık olarak planlanmalıdır (Bodenheimer ve ark. 2002b). Literatürde başarılı ve etkin bir kronik hastalık yönetimi ekibinde; hemşire vaka yöneticisi, uzman hekim, eczacı, sosyal çalışmacı, profesyonel olmayan/gönüllü yardımcı sağlık çalışanları yer almaktadır (Wagner 2000). Ekipte vaka yöneticisi olarak hemşirelerin yer alması önemlidir (Bonomi ve ark. 2002; Epping-Jordan, Pruitt, Bengoa ve Wagner 2004; Solberg ve ark. 2005; Wagner ve ark. 2001; Zwar ve ark. 2006). Vaka yöneticisi olan hemşire; hastayı hastalığına göre sağlık kayıtlarına dahil eder, diğer ekip üyeleriyle iletişime geçer, temel tanılamayı yapar, semptomları takip eder, ilaç etkilerini tanılar, tedavinin eksikliklerini ve hasta sorunlarını belirler, öz-yönetim desteğini başlatır ve devamı için hastayı destekler, her ziyaretten sonra hastanın istek ve ihtiyaçlarını belirler, telefonla ve ziyaretlerle (izlem) bakımın sürekliliğini sağlar (Solberg ve ark. 2005; Wagner 2000) Etkili bir vaka yönetimi için hemşirenin gerekli beceri ve eğitime sahip olması, ekip üyeleriyle işbirliği ve olumlu bir iletişim içinde olması gerekmektedir (Wagner 2000).

$\mathrm{Bu}$ bileşen ekibin rollerinin tanımlanmasının yanı sıra; bakım standartlarının geliştirilmesi ve yaygınlaştırıl- 
ması, kanıta dayalı klinik ve hasta eğitim rehberlerinin oluşturulması, oluşturulan rehberlerin uygulamada kullanılması, bakım engellerinin tanımlanması (hastalık hakkında yetersiz bilgi, farkındalığın az olması, eğitim hizmetlerinin farkında olmama, sosyal destek yetersizliği gibi) ve bu konuda gerekli düzenlemelerin planlanmasını içermektedir (Barr ve ark. 2003; Stellefson ve ark. 2013; Zwar ve ark. 2006).

\section{4. Öz-Yönetim Desteği (Self-Management Support):}

Öz-yönetim; kişinin bir görevi uygun şekilde yönetmesi için gözlemleme, bilgi paylaşımı, işbirlikçi kararlar alma, amaç belirleme, eylemleri planlama ve gerçekçi tepkiler verme sürecidir (Clark ve Gong 2000; Moroz 2007). İnsanlar uzun yıllar kronik hastalıkla yaşadıkları için, birey için öz-yönetim günlük hayatın bir parçasıdır ve hastalar kendi bakımlarında merkezi roldedir (Lorig ve Holman 2003). Öz-yönetim desteği, kronik hastalığı olan birey ve ailesine hastalık yönetiminde güven ve beceri kazandırmayı, öz-bakımı sürdürmek için kaynak sağlamayı, karar verme sürecinde desteklemeyi, problemleri tanılama ve baş etmede yardımcı olmayı, toplum kaynaklarına sevk etmeyi ve sürecin düzenli olarak tanılanmasını içermektedir (Epping-Jordan ve ark. 2004; Moroz 2007; Zwar ve ark. 2006).

Özellikle hasta eğitimi ve motivasyonel danışmanlığın bu aşamada çok yararlı olduğu belirtilmektedir (Zwar ve ark. 2006). Çeşitli araştırma raporlarında öz-yönetim desteğinin kronik hastalık yönetiminin merkezinde yer aldığı, en iyi bakım sonuçları elde etmek için gerekli olduğu ve uzun dönemli yararları için hasta ve profesyoneller arasında sürekli etkileşimi gerektirdiği kabul edilmektedir (Epping-Jordan ve ark. 2004; Moroz 2007).

\section{Karar Verme Desteği (Decision Support): Karar} verme desteği her zaman yoğun uzmanlık gerektirmeyen bir boyuttur ve uzaktan sade bir telefon çağrısı ile uygulanabilir (Bodenheimer ve ark. 2002a). Hasta ve sağlık bakım profesyonelleri arasındaki etkileşimlerde kanıta dayalı protokoller, hatırlatıcı sistemler, destekleyici eğitimler ve klinik uygulama rehberleri kul- lanılmalıdır. Kronik hastalık yönetimi ve klinik bilgi sistemlerinin etkin kullanımı için, hekim ve hemşirelerin eğitimlerini destekleyen programlar geliştirilmeli ve desteklenmeli ve bireyin tedavi bakımı ile ilgili kararlara katılımı sağlanmalıdır. Uzmanların sağlık ekibi içerisinde entegrasyonunu sağlama, rehberlik ve danışmanlığ 1 da bu bileşen için son derece önemlidir (Bonomi ve ark. 2002; Hung ve ark. 2007; ICN 2010; Landon ve ark. 2007; Tsai, Morton, Mangione ve Keeler 2005; Zwar ve ark. 2006).

Kronik hastalığg olan bireylere karar verme desteğinin sağlanmasında sağlık profesyonellerinin eğitim ve rehberler ile desteklenmesinin yanı sıra, bilgisayar ortamında geliştirilmiş çeşitli karar destek sistemlerinin kullanılması da yararlı olabilmektedir. Klinik karar destek sistemleri, problem çözme işlemi sırasında alternatif çözümleri test etme ve verileri yeniden gözden geçirme imkanı veren, bilginin paylaşım hızının artmasını, disiplinler arası ortak çözümler üretilmesini ve maliyet kontrolü sağlayan bir sistemdir (Aydın 2011; Özata ve Aslan 2004). Klinik tanının konulması, ilaç etkileşimleri ve yan etkileri, ilaç dozajı ayarlama, acil durumların tespiti ve uyarısı gibi uygulamaları içeren çeşitli modelleri bulunmaktadır (Özata ve Aslan 2004).

Hemşirelik uygulamalarında da gelişen teknolojiyle birlikte elektronik karar destek sistemlerinin kullanımı önemini giderek artıran ve konu ile ilgili çalışmaların günümüzde hız kazandığı bir konudur. Ancak bu sistemlerinin entegrasyonuna yönelik çalışmalar; özellikle mali yetersizlikler, sistem kullanıcılarının bilgisayar kullanımı ile ilgili yeterli bilgi ve beceriye sahip olmamaları, sistemi kullanmada çeşitli endişelere sahip olmaları nedeniyle dünyada ve ülkemizde istendik düzeye henüz ulaşamamıştır. Bu doğrultuda bilgisayar kullanımı ve bilişim konularında hemşire eğitiminin sağlanması, hemşirelerin sistemin yapılanması, kullanılması ve değerlendirilmesi aşamalarında aktif katılımının sağlanması ve uygulamaları geliştirecek araştırmaların yapılması önerilmektedir (Aydın 2011).

\section{Klinik Bilgi Sistemleri (Clinical Information}

Systems): Etkili ve verimli hizmet sunmada, hastalık 
yönetimini kolaylaştırmada hasta popülasyonu hakkında gerekli ve yararlı veriyi zamanında sağlayan, organize eden bir sistemdir (Epping-Jordan ve ark. 2004). Kronik Bakım Modeli'nin merkezi bir özelliği olan kayıtların özellikle bilgisayar ortamında toplanması ve yeni teknolojilerin kullanılması önerilmektedir (Bonomi ve ark. 2002; Bodenheimer ve ark. 2002a; Epping-Jordan ve ark. 2004).

Klinik bilgi sistemleri; elektronik sağlık kayıtları, klinik karar destek sistemleri, hemşire bilgi sistemleri, görüntü yönetim ve depolama sistemleri, klinik iletişim sistemleri, teletıp, vaka bilişimi, sanal gerçeklik uygulamaları, akıllı kart uygulamaları, hastane bilgi sistemleri, klinik k1lavuzlar ve bakım haritaları gibi bileşenlerden oluşmaktadır (Ömürbek, Demirgubuz ve Tunca 2013). Literatürde elektronik sağlık kayıtlarının kullanımının; hasta güvenliğini artırdığı, sağlık bakımı ve kayıt kalitesini iyileştirdiği, bakım maliyetini düşürdüğü, kanıta dayalı uygulamalar için kaliteli veri sağladığ 1 , verilere ulaşımı kolaylaştırdığı, hekim hemşire işbirliğini artırdığı belirtilmektedir (Hayrinen, Saranto ve Nykanen 2008; TTB 2011b).

Bilgi ve iletişim teknolojilerinde hemşirelikle ilgili alanlar ve işlemleri kapsayan hemşire bilgi sistemleri; bilgilerin işlenmesini ve yönetimini kolaylaştırarak hastanın tanımlanması, izlenmesi, bakım planlarının hazırlanması, bakımın sunulması ve değerlendirilmesi gibi hemşirelik işlemlerinin kolay ve hızl1ca yapılmasına olanak sağlar (Saba 1997). Hemşirelik Minimum Veri Seti, Perioperatif Hemşirelik Veri Seti, Tele-Sağlık gibi sistemler, hemşirelik uygulamalarını desteklemenin yanı sıra hastane bilgi sistemleri için de temel oluşturmaktadır (Ay 2009). Ancak ülkemizde hastane bilgi yönetim sistemleri adı altında kullanılan yazılımların çoğunluğunun; faturalama sistemleri, stok kontrolü ve personel işlemleri gibi modülleri kapsadığı ve elektronik sağlık kaydını ve klinik karar destek sistemlerini içeren sağlık bilgi yönetim sistemlerinin yok denecek kadar az olduğu belirtilmektedir (TTB 2011b). Ayrıca hemşire kayıtları ile diğer sağlık profesyonellerinin kayıtları arasındaki bağlantının ek- sik olması da hemşire kayıtlarının etkin paylaşılmasın1 engellemektedir (Ay 2009).

\section{KRONIKK BAKIM MODELI'NIN BÍLEŞENLERINNE İLIŞKİN KANITLAR}

Literatürde Kronik Bakım Modeli'ne dayalı başarılı bir kronik hastalık yönetimi için tüm bileşenlerin birlikte ele alınması önerilmekle birlikte, özellikle "săglık hizmetleri sunum planı" ve "öz-yönetim desteği”" bileşenlerinin bakım sürecini geliştirme ve hasta sonuçlarını iyileştirmede son derecede önemli olduğu ve bu konuda çok sayıda kanıt bulunduğu belirtilmektedir (Dorr ve ark. 2006; Tsai ve ark. 2005; Zwar ve ark. 2006). Kronik Bakım Modeli bileşenlerinin etkinliğini gösteren girişim örnekleri ve bu girişimlerin sonucunda beklenen sonuç kriterleri Tablo 1'de özetlenmektedir. Tablo 1'den elde edilen bilgiler ışığında, diğer bileşenlerin uygulamadaki etkinliğinin değerlendirilmesi ile ilgili yeterli kanıta ulaşıldığı ancak "sağlık bakım organizasyonu” ve "toplum kaynaklarl ve politikalar" bileşenlerinin etkinliğini gösterecek araştırma kanıtlarının eksik olduğu görülmektedir (Zwar ve ark. 2006). Tsai ve ark. (2005) meta-analiz çalışmasında da benzer sonuçlara ulaşıldığı belirtilmekte ve bu iki bileşenin uygulamada kullanımı konusunda yeni çalışmalar yapılması önerilmektedir.

\section{SONUÇ VE ÖNERÍLER}

Sonuç olarak; günümüzde kronik hastalık yükünün giderek artması ile birlikte kronik hastalıkların özyönetimi ile birinci basamak odaklı ve toplum temelli hastalık yönetimi programlarının önemi artmıştır. Kronik hastalık yönetiminde bir rehber olarak geliştirilen Kronik Bakım Modeli; bakımının sürekliliğinin sağlanmasında, bireyler ile sağlık profesyonelleri arasındaki işbirliğinin ve etkileşimin geliştirilmesinde, bak1mın kalitesinin artırılmasında, maliyet-etkililiğin sağlanmasında, bakıma aktif katılımın sağlanmasında sağlık profesyonelleri tarafindan kullanılabilir. Bu doğrultuda sağlık profesyonellerinin ve özellikle de kronik hastalık yönetimi konusunda anahtar rolde olan hemşirelerin, farkındalığının artırılması, mezuniyet öncesi ve 
Tablo 1. Kronik Bakım Modeli Bileşenlerinin Etkinliğini Gösteren Girişimler ve Sonuçlar

\begin{tabular}{|c|c|c|}
\hline Model Bileşenleri & Model Bileşeninin Etkinliğini Gösteren Girişimler & $\begin{array}{l}\text { Model Bileşeninin Etkinliğini } \\
\text { Gösteren Sonuçlar }\end{array}$ \\
\hline Öz-Yönetim Desteği & $\begin{array}{l}\text { * Hasta eğitim toplantıları } \\
* \text { Motivasyonel danışmanlık } \\
* \text { Eğitim materyallerinin dağıtılması }\end{array}$ & $\begin{array}{l}\text { - Hastalığın fizyolojik ölçümleri, } \\
\text { - Hastanın yaşam kalitesi, } \\
\text { - Hastanın sağlık durumu, } \\
\text { - Hasta fonksiyonel durumu, } \\
\text { - Hasta memnuniyeti, } \\
\text { - Hastanın risk davranışları } \\
\text { - Hastanın bilgisi, } \\
\text { - Hizmet kullanımı, } \\
\text { - Tedaviye uyum }\end{array}$ \\
\hline Sağlık Hizmetleri Sunum Planı & * Multidisipliner ekip & $\begin{array}{l}\text { - Hastalığın fizyolojik ölçümleri } \\
\text { - Profesyonellerin rehberlere uyumu } \\
\text { - Hastaların hizmet kullanımı }\end{array}$ \\
\hline Karar Verme Desteği & $\begin{array}{l}* \text { Kanıta dayalı rehberlerin uygulanması } \\
* \text { Profesyonellerle eğitim toplantıları } \\
* \text { Eğitim materyallerinin profesyonellere dağıtılması }\end{array}$ & $\begin{array}{l}\text { - Profesyonellerin rehberlere uyumu } \\
\text { - Hastalığın fizyolojik ölçümleri }\end{array}$ \\
\hline Klinik Bilgi Sistemleri & * Denetim ve geri bildirim & - Profesyonellerin rehberlere uyumu \\
\hline Sağlık Bakım Organizasyonu & \multicolumn{2}{|l|}{ Bileşenin etkinliği ile ilgili yetersiz kanıt } \\
\hline Toplum Kaynakları ve Politikalar & \multicolumn{2}{|l|}{ Bileşenin etkinliği ile ilgili yetersiz kanıt } \\
\hline
\end{tabular}

Kaynak: Zwar, N. ve ark. (2006). A Systematic review of chronic disease management. Research Centre for Primary Health Care and Equity. Sidney: Australian Primary Health Care Research Institute, 1-67, http://files.aphcri.anu.edu.au/research/fi nal_25_zwar_ pdf_85791.pdf (08.09.2013).

sonras1 eğitimlerde kronik hastalık yönetimi programlarının yer alması, bu konuda yeterli sayıda ve uygun insan gücünün sağlanması önem taşımaktadır.

\section{KAYNAKLAR}

Adams, S. G. ve ark. (2007). Systematic review of the chronic care model in chronic obstructive pulmonary disease prevention and management. Arch Intern Med, 167: 551-561.

Akalın, E., Durusu Tanrı̈ver, M., Sayran, F. (2012). Sürdürülebilir Sağlık Sistemi İçin Kronik Hastalık Yönetiminde Elektronik Sağlık Kayıtlarının Rolü. Sis Matbaacılık Prom. Tanıtım Hiz. Tic. Ltd. Şti., 25-73.

Akdağ, R. (Ed.) (2008). Türkiye Sağlıkta Dönüşüm Programı İlerleme Raporu. T.C. Sağlık Bakanlığı Yayınları, 47-49.

Ay, F. (2009). Uluslararası elektronik hasta kayıt sistemleri, hemşirelik uygulamaları ve bilgisayar ilişkisi. Gülhane Tıp Dergisi, 51: 131-136.

Aydın, N. (2011). Klinik karar destek sistemleri ve hemşirelikte kullanımı. Hemşirelikte Ĕ̈itim ve Araştırma Dergisi, 8(3): 59-63.

Barr, V. J. ve ark. (2003). The expanded chronic care model: An integration of concepts and strategies from population health promotion and the chronic care model. Hospital Quartery, 7(1): 73-82.
Beaglehole, R. ve ark. (2008). Improving the prevention and management of chronic disease in low income and middle-income countries: A priority for primary health care. Lancet, 372: 940-949.

Becker, D. M. ve ark. (1998). Nurse-mediated cholesterol management compared with enhanced primary care in siblings of individuals with premature coronary disease. Arch Intern Med, 158: 1533-1539.

Bodenheimer, T., MacGregor, K., Stothart, N. (2005). Nurses as leaders in chronic care. Their role is pivotal in improving care for chronic diseases. BMJ, 330: 612-613.

Bodenheimer, T., Wagner, E. H., Grumbach, K. (2002a). Improving primary care for patients with chronic illness. JAMA, 288(14): 1775-1779.

Bodenheimer, T., Wagner, E. H., Grumbach, K. (2002b). Improving primary care with chronic illness: The chronic care model, part 2. JAMA, 288(15): 1909-1914.

Bonomi, A. E., Wagner, E. H., Glasgow, R. E., VonKorff, M. (2002). Assessment of chronic illness care (ACIC): A practical tool to measure quality improvement. Health Services Research, 37(3): 791-820.

Bora Başara, B., Dirimeşe, V., Özkan, E., Varol, Ö. (2006). Türkiye'de ölümler 2004. Ünüvar, N., Mollahaliloğlu, S., Yardım, N. (Eds.). Türkiye Hastalık Yükü Çalışması 2004. Aydoğdu Ofset Matbaacılık San. ve Tic Ltd. Şti., Ankara, 4-12. 
Braddock, C. H., Edwards, K. A., Hasenberg, N. M., Laidley, T. L., Levinson, W. (1999). Informed decision making in outpatient practice. JAMA, 282: 2313-2320.

Carlini, B. H., Schauer, G., Zbikowski, S., Thompson, J. (2010). Using the chronic care model to address tobacco in health care delivery organizations: A pilot experience in washington state. Health Promotion Practice, 11(5): 685-693.

Clark, N. M., Gong, M. (2000). Management of chronic disease by practioners and patients: Are we teaching the wrong things? $B M J$, 320: 572-575.

Coleman, K., Austin, B. T., Brach, C., Wagner, E. H. (2009). Evidence on the chronic care model in the new millennium. Health Affairs, 28(1): 75-85.

Cranston, J. M. (2006). Models of chronic disease management in primary care for patient with mild to modetare asthma or copd, 1-114, http://files.aphcri.anu.edu.au/research/full_report_84547.pdf (15.09.2013).

Davis, R. M., Wagner, E. H., Groves, J. (1999). Managing chronic disease. $B M J, 318(7191)$ : 1090-1091.

Demirağ, S. A. (2009). Kronik hastalıklar ve yaşam kalitesi. Sağllklı Yaşam Tarzı Dergisi, 1(1): 58-65.

Dorr, D. A. ve ark. (2006). Implementing a multidisease chronic care model in primary care using and technology. Disease Management, 9(1): 1-16.

Duangbubha, S., Hanucharurnkul, S., Pookboonmee, R., Orathai, P., Kiatboonsri, C. (2013). Chronic Care Model Implementation and Outcomes among Patient with COPD in care teams with and without advanced practice nurses. Pacific Rim Int J Nursing Res, 17(2): 102-116.

Epping Jordan, J. E., Pruitt, S. D., Bengoa, R., Wagner, E. H. (2004). Improving the quality of health care for chronic conditions. Qual Saf Health Care, 13: 299-305.

Erkoç, Y., Yardım, N. (2011). Türkiye'de Bulaşıcı Olmayan Hastalıklar ve Risk Faktörleri ile Mücadele Politikaları. T.C. Sağlık Bakanlığg Yayınları, Anıl Matbaası, 50-119.

Geyman, J. P. (2007). Disease management: Panacea, another false hope, or something in between? Ann Fam Med, 5: 257-260.

Glasgow, R. E., Orleans, T. C., Wagner, E. H. (2001). Does the chronic care model serve also as a template for improving prevention? The Milbank Quarterly, 79(4): 579-612.

Haskett, T. (2006). Chronic illness management: Changing the system. Home Health Care Management Practice, 18: 492-496.
Hayrinen, K., Saranto, K., Nykanen, P. (2008). Definition, structure, content, use and impacts of electronic health records: A review of the research literature. Int J Med Inform, 77(5): 291-304.

Heisler, M., Bouknight, R. R., Hayward, R. A., Smith, D. M., Kerr, E. A. (2002). The relative importance of physician communication, participatory decision making, and patient understanding in diabetes self-management. J Gen Intern Med, 17: 243252 .

Hennessey, B., Suter, P., Harrison, G. (2010). The home-based chronic care model: A platform for partnership for the provision of a patient centered medical home. CARING, 29(2): 18-24.

Hung, D. Y. ve ark. (2007). Rethinking prevention in primary care: Applying the chronic care model to address health risk behaviors. The Milbank Quarterly, 85(1): 69-91.

International Council of Nurses (ICN) (2010). Delivering Quality, Serving Communities: Nurses Leading Chronic Care, 1-69, http://www.icn.ch/images/stories/documents/publications/ind/indkit2010.pdf (15.09.2013).

Landon, B. E. ve ark. (2007). Improving the manager of chronic disease at community health centers. The New England Journal Medicine, 356: 921-934.

Lorig, K. R., Holman, H. R. (2003). Self-management: History, definition, outcomes, and mechanisms. Ann Behav Med, 26(1): 1-7.

Mcevoy, P., Barnes, P. (2007). Using the chronic care model to tackle depression among older adults who have long-term physical conditions. Journal of Psychiatric and Mental Health Nursing, 14: $233-238$

Mollahaliloğlu, S. ve ark. (Eds.) (2007). Türkiye’de Sağlı̆ga Bakış 2007. Bölük Ofset Matbaacılık, Ankara.

Moroz, S. A. M. (2007). Improving chronic illness care: The chronic care model. Current Issues in Cardiac Rehabilitation and Prevention, 15(1): 2-5.

Ömürbek, N., Demirgubuz, M. Ö., Tunca, M. Z. (2013). Hastanelerdeki bilişim sistemlerinden klinik bilgi sistemlerinin kullanımına yönelik bir araştırma: Denizli ve Isparta örneği. Selçuk Üniversitesi İktisadi ve İdari Bilimler Fakültesi Sosyal ve Ekonomik Araştırmalar Dergisi, 13(25): 301-328.

Özata, M., Aslan, Ş. (2004). Clinical decision support systems and model applications. The Medical Journal of Kocatepe, 5: 11-17.

Piatt, G. A., Zgibor, J. C. (2007). Current opinion in endocrinology. Diabetes \& Obesity, 14: 158-165.

Renders, C. M. ve ark. (2001). Interventions to improve the management of diabetes mellitus in primary care, outpatient and community settings. The Cochrane Database Syst Rev, 1: 1-140. 
Rosemann, T., Laux, G., Szecsenyi, J., Grol, R. (2008). The Chronic Care Model: Congruency and predictors among primary care patients with osteoarthritis. Qual. Saf. Health Care, 17: 442-446.

Rothman, A. A., Wagner, E. H. (2003). Chronic illness management: What is the role of primary care? Ann Intern Med, 138: 256261.

Saba, V. K. (1997). A look at nursing informatics. International Journal of Medical Informatics, 44: 57-60.

Sadur, C. N. ve ark. (1999). Diabetes management in a Health Meintenance Organization effi cacy of care management using cluster visits. Diabetes Care, 22: 2011-2017.

Smidth, M., Christensen, M. B., Olesen, F., Vedsted, P. (2013). Developing an active implementation model for a chronic disease management program. International Journal of Intergrated Care, 13: $1-16$.

Solberg, L. I., Trangle, M. A., Wineman, A. P. (2005). Follow-up and follow- through of depressed patients in primary care: The critical missing components of quality care. $J$ Am Board Fam Pract, 18: 520-527.

Stellefson, M., Dipnarine, K., Stopka, C. (2013). The chronic care model and diabetes management in US primary care settings: A systematic review. Prev. Chronic Dis, 10: 1-21.

Suter, P., Hennessey, B., Florez, D., Suter, W. N. (2011). The HomeBased Chronic Care Model: Redesigning home health for high quality care delivery. Chronic Respiratory Disease, 8(1): 43-52.

T. C. Sağlık Bakanlığı (SB) (2008). Türkiye Kalp ve Damar Hastalıkları Önleme ve Kontrol Programı. Temel Sağlık Hizmetleri Genel Müdürlüğü Yayını, Ankara. 5-89.
Tsai, A. C., Morton, S. C., Mangione, C. M., Keeler, E. B. (2005). A meta- analysis of interventions to improve care for chronic illnesses. Am J Manag Care, 11: 478-488.

Türk Tabipler Birliği (TTB) (2011a). 2011 Seçimlerine Giderken Türkiye'de Sağllk. 1. basım. Türk Tabipler Birliği Yayınları, Ankara. 7-16.

Türk Tabipler Birliği (TTB) (2011b). Hasta Güvenliği: Türkiye ve Dünya. 1. basım, Türk Tabipler Birliği Yayınları, Ankara. 139-147.

Wagner, E. H. (2000). The role of patient care teams in chronic disease management. BMJ, 320: 569-572.

Wagner, E. H. (2002). The Changing Face of Chronic Disease Care. In: Schoeni, P.O. (Ed.). Curing the System Stories of Change in Chronic Illness Care. The National Coalition on Health Care and the Institute for Healthcare Improvement. Washington: The National Coalition on Health Care Institute, 2-5.

Wagner, E. H. (2004). Chronic disease care. BMJ, 328: 177-178.

Wagner, E. H. ve ark. (2001). Improving chronic illness care: Translating evidence into action interventions that encourage people to acquire self-management skills are essential in chronic illness care. Health Affairs, 20(6): 64-78.

World Health Organization (WHO) (2011). Global status report on noncommunicable diseases 2010: Burden, mortality, morbidity and risk factors. WHO Library Cataloguing in Publication Data, Italy.

Zwar, N. ve ark. (2006). A Systematic review of chronic disease management. Research Centre for Primary Health Care and Equity. Sidney: Australian Primary Health Care Research Institute, 1-67, http://fi les.aphcri.anu.edu.au/research/fi nal_25_zwar_ pdf_85791.pdf (08.09.2013). 